Research Article

\title{
Evaluation of the Occurrence of Anesthesia Awareness with Recall in Opium- Addicted and Non-Addicted Patients Undergoing Pelvic and Abdominal Surgery
}

\author{
Seyyedeh Mahrokh Alinaghi Madah ${ }^{1}$, Zahra Yousefi*² ${ }^{2}$ Fozieh Bakhsha ${ }^{2}$, Zahra Heidari ${ }^{2}$, \\ Solamaz Halakou ${ }^{2}$, Seyyed Yaghoob Jafari ${ }^{2}$, Sina Mohajernoei ${ }^{1}$ \\ 1. School of Medicine, Golestan University of Medical Sciences, Gorgan, Iran \\ 2. School of Paramedicine, Laboratory Sciences Research Center, Golestan University of \\ Medical Sciences, Gorgan, Iran \\ *Correspondence: Zahra Yousefi, School of Paramedicine, Golestan University of Medical \\ Sciences, Gorgan, Iran. \\ Email: stu.yousefi@yahoo.com \\ Tel: +9832456102
}

Received February 6, 2021

Accepted February 24, 2021

\begin{abstract}
Background and objectives: Intraoperative awareness is accidental or unintentional awareness during general anesthesia that occurs when complete anesthesia has not been achieved. The aim of this study was to investigate the occurrence of awareness with recall during general anesthesia in opium-addicted and non-addict patients undergoing abdominal and pelvic surgeries.

Methods: The study population consisted of patients undergoing abdominal and pelvic surgeries under general anesthesia in two hospitals in Gorgan, Northeast of Iran. Data were collected 2036 hours after the surgery using a three-part questionnaire on demographic information, surgery and anesthesia details and anesthesia awareness and recall of events. Data were analyzed in SPSS (version 18) using the Chi-square test.

Results: Of 206 patients, 53.9\% were male and 56.3\% were undergoing abdominal surgery. None of the patients in the two groups felt hearing, pain, cold or heat during anesthesia, and neither of them dreamed or recalled any event during the anesthesia and surgery period. There was no statistically significant difference between the two groups in terms of anesthesia awareness with recall. According to the patients, the night before the operation, opium addicts were more anxious the night before the surgery and felt more pain right after the surgery.

Conclusion: There is no statistically significant difference in terms of occurrence of anesthesia awareness between opium-addicted and non-addicted patients undergoing pelvic and abdominal surgeries. However, opium addicts experience significantly higher level of anxiety the night before surgery compared to non-addicts. In addition, opium addicts experience more pain immediately after recovery.
\end{abstract}

Keywords: Anesthesia Awareness, Recall, General anesthesia, Opium addiction

\section{DOI: 10.29252/Jcbr.5.1.7}

This work is licensed under a Creative Commons Attribution 4.0 License.

(C) The authors 


\section{INTRODUCTION}

The term "anesthesia awareness" is a universally accepted phenomenon defined as recalling events during general anesthesia after surgery $(\underline{1}, \underline{2})$. General anesthesia is a drug-induced reversible condition characterized by unconsciousness, amnesia, analgesia and akinesia (ㅁ) created by a balance between the amount of anesthetics administered and the patient's arousal (1). Recall is the patient's ability to retrieve memories that are assessed by the patient's reports of past events, especially those that occurred during general anesthesia $(\underline{4}, \underline{5})$. The prevalence of anesthesia awareness varies from $0.11 \%$ to $43 \%$ in adults and $5 \%$ in children (ㅁ-ㄱ).

Causes of awareness and recall during general anesthesia include the followings: 1 . Light anesthesia for some surgeries such as cesarean section and emergency surgeries; 2 . Increased need for anesthetics for patients who are often resistant to anesthetics, such as young patients and consumers of tobacco, alcohol, narcotics or amphetamines. 3 . Malfunction of the anesthesia machine; 4. Not delivering enough anesthetics to the patient due to an empty evaporator or $\mathrm{N} 2 \mathrm{O}$ cylinder.

If the patient is awake during the operation and able to hear conversations, he will feel weak, paralyzed, helpless, anxious and afraid of death. It may also lead to a series of complications including sleep disturbances, nightmares and anxiety during the day, which may be transient or long term. In severe conditions, it may lead to post-traumatic stress disorder $(\underline{8}, \underline{9})$. The patient also fears that this may be repeated in the future if anesthesia is needed (9). The occurrence of anesthesia awareness depends on the anesthesia methods and the study population. For example, opium addicts require a higher dose of anesthetics because of tolerance to anesthetics (10-12). The issue of anesthesia awareness is currently being reevaluated due to the suggestions of recent studies that consciousness is a common occurrence and associated with unintended consequences (13). Identifying risk factors and possible reasons for the occurrence of anesthesia awareness may help prevent this issue and its complications. Determining the proper medication regimen will provide a safe and mentally healthy anesthesia for the patient, which will ultimately improve health and reduce the cost of treatment in patients undergoing surgery. Since drug addiction can increase the likelihood of awareness during anesthesia, the present study was conducted to investigate the occurrence of awareness and recall during general anesthesia in opium-addicted and non-addicted patients undergoing abdominal and pelvic surgeries.

\section{MATERIALS AND METHODS}

In this study, the study population consisted of patients undergoing elective abdominal and pelvic operations under general anesthesia in the 5 Azar and Sayyad Shirazi Education hospitals in Gorgan, Iran. Written consent was obtained from all participants and the study received approval from the Ethics Committee of Goletan University of Medical Sciences, Gorgan, Iran. Inclusion criteria were classes 1, 2 and 3 anesthesia, age of over 16 years, verbal and auditory health and lack of mental illness. Exclusion criteria included emergency surgeries, postoperative stay of less than 24 hours and addiction to alcohol, methamphetamines, etc.

Based on the study of Malek et al. and considering the prevalence rate of $13 \%$ and $1.6 \%$ anesthesia awareness in opiumaddicted and non-addict individuals, $80 \%$ power and 5\% error, sample size of 78 was considered for each study group. Taking into account the exclusion of study subjects, with a 30\% increase in sample size, 103 people were considered for each group. Subjects were enrolled via convenience sampling.

The patients were examined by an anesthesiologist before surgery. After 10 hours fasting, the patients entered the 
operating room in supine position and the drugs were administered prior to the operation. Preoperative prodrugs including midazolam $(2.5 \mathrm{mg})$, fentanyl $(25-100 \mu \mathrm{g})$ and metoclopramide $(10 \mathrm{mg})$ or ondansetron (4 mg) were used. Anesthesia was induced with $3-5 \mathrm{mg} / \mathrm{kg}$ nesdonal and $0.5-4 \mathrm{mg} / \mathrm{kg}$ atracurium muscle relaxant, and maintained with 1.5 MAC isoflurane and nitrous oxide (50\%). To restore relaxant effects, 0.05-0.07 $\mathrm{mg} / \mathrm{kg}$ neostigmine and $0.1-0.2 \mathrm{mg} / \mathrm{kg}$ atropine were administered. Preoperative fluid therapy was performed equally for all patients by calculating the amount of fluid required for the patient and considering the duration of fasting and the patient's bleeding rate. During general anesthesia, the patients underwent standard monitoring including continuous monitoring of heart rate and electrical activity, blood pressure and red blood cell oxygen saturation. The results were recorded every 15 minutes.

Data were collected using a three-part questionnaire on demographic information, surgical and anesthesia information (ASA score, duration of anesthesia, administered drugs as well as duration, site and type of surgery) and anesthesia awareness with recall. The questionnaire has been previously used in studies by Lio et al. (14) and Shahi et al. (15). The first part of the questionnaire was completed during patient admission by a trained researcher. The second part of the questionnaire was completed based on the anesthesia data sheet after the patient recovered. The third part of the questionnaire was completed 2036 hours after the surgery and after complete awakening of patients (15) through interview. The task of researcher was to simply record feeling and perceptions of the patients during surgery. Therefore, the patients' statements were not scored nor interpreted. The following yes or no questions were used in the questionnaire:

1. During the operation, did you notice any of the following: sounds, sight, being touched by others, pain, cold, heat and dreaming?

2. How was your mental state before the surgery? Calm, anxious, worried, scared, drowsy, hungry, in pain.

3. What was the last thing you remember before the anesthesia?

4. What is the first thing you remember after the surgery?

5. Can you remember anything between these two events?

Collected data were described as frequency and percentage. The data were analyzed in SPSS software (version 18) using the Chisquare test.

\section{RESULTS}

Of 206 subjects enrolled in the study, $53.9 \%$ were men and $56.3 \%$ were undergoing abdominal surgery. In addition, $5.8 \%$ of the subjects were alcohol drinker (Table 1). 
Table 1. Demographic characteristics of the study subjects

\begin{tabular}{|c|c|c|c|}
\hline \multicolumn{2}{|c|}{ Variable } & Number & Percent \\
\hline \multirow{2}{*}{ Gender } & Male & 111 & 53.9 \\
\hline & Female & 95 & 46.1 \\
\hline \multirow{2}{*}{ Hospital } & 5 Azar & 90 & 43.7 \\
\hline & Sayyad Shirazi & 116 & 56.3 \\
\hline \multirow{3}{*}{$\mathbf{A S A}$} & 1 & 93 & 45.1 \\
\hline & 2 & 102 & 49.5 \\
\hline & 3 & 11 & 5.3 \\
\hline \multirow{6}{*}{ Education level } & Illiterate & 15 & 7.3 \\
\hline & Primary & 18 & 8.7 \\
\hline & High school diploma & 55 & 26.7 \\
\hline & Associate Degree & 54 & 26.2 \\
\hline & Bachelor's Degree & 58 & 28.2 \\
\hline & Postgraduate & 6 & 2.9 \\
\hline \multirow{2}{*}{ History of surgery } & Yes & 117 & 56.8 \\
\hline & $\mathrm{No}$ & 89 & 43.2 \\
\hline \multirow{2}{*}{ Surgery site } & Abdominal & 116 & 56.3 \\
\hline & Pelvic & 90 & 43.7 \\
\hline \multirow{7}{*}{ Occupation } & Unoccupied & 28 & 13.6 \\
\hline & Farmer & 16 & 7.8 \\
\hline & Teacher & 26 & 12.6 \\
\hline & Freelance & 40 & 19.4 \\
\hline & Military & 6 & 2.9 \\
\hline & Homemaker & 65 & 31.6 \\
\hline & Retired & 25 & 12.1 \\
\hline \multirow{2}{*}{ Opium use } & Yes & 104 & 50.5 \\
\hline & No & 102 & 49.5 \\
\hline Group & Opium addict & \multicolumn{2}{|c|}{ Non-addict } \\
\hline Age (years) & $45.88 \pm 16.79$ & \multicolumn{2}{|c|}{$37.74 \pm 14.96$} \\
\hline Body mass index $\left(\mathrm{kg} / \mathrm{m}^{2}\right)$ & $24.1 \pm 4.26$ & \multicolumn{2}{|c|}{$23.88 \pm 3.05$} \\
\hline
\end{tabular}

The patients in both groups did not experience hearing, sight, pain, cold, heat and touch during anesthesia and neither of them reported dreaming or any memory of the surgery and anesthesia. However, opium addicts were significantly more anxious at the night before surgery and felt more pain right after the surgery compared to non-addicted patients (Table 2). 
Table 2. Comparison of mental state of opium-addicted and non-addict patients at different times from the night before surgery to after surgery according to the patients' perception.

\begin{tabular}{|c|c|c|c|c|c|c|c|c|c|c|c|c|c|c|c|}
\hline Group & \multicolumn{7}{|c|}{ Opium addicts } & \multicolumn{7}{|c|}{ Non-addicts } & \multirow{2}{*}{$\begin{array}{c}\text { P- } \\
\text { value } \\
\text { Chi- } \\
\text { square }\end{array}$} \\
\hline & Calm & Nervous & Worried & Afraid & Sleepy & Hungry & $\begin{array}{l}\text { In } \\
\text { pain }\end{array}$ & Calm & Nervous & Worried & Afraid & Sleepy & Hungry & $\begin{array}{l}\text { In } \\
\text { pain }\end{array}$ & \\
\hline $\begin{array}{c}\text { The night } \\
\text { before } \\
\text { surgery }\end{array}$ & 11 & 46 & 9 & 16 & - & - & 22 & 16 & 38 & 17 & 8 & 4 & 2 & 17 & 0.03 \\
\hline $\begin{array}{c}\text { Surgery } \\
\text { waiting } \\
\text { room }\end{array}$ & 9 & 45 & 28 & 15 & 3 & 3 & 1 & 18 & 43 & 22 & 13 & - & 5 & 1 & 0.28 \\
\hline $\begin{array}{c}\text { Anesthesia } \\
\text { induction }\end{array}$ & 7 & 47 & 31 & 12 & 3 & 4 & - & 14 & 42 & 28 & 13 & - & - & 5 & 0.01 \\
\hline $\begin{array}{l}\text { After the } \\
\text { surgery }\end{array}$ & 30 & 1 & 4 & 5 & 13 & 10 & 41 & 24 & 2 & 1 & 6 & 11 & 10 & 48 & 0.75 \\
\hline
\end{tabular}

Pain and conversation with the nurse were the first things opium-addicted and non-addict patients remembered right after the surgery, respectively. Moreover, opium addicts reported fear of surgery and possible complications including disability as the main issues of concern between the night before surgery and anesthesia. In non-addicts, lack of general knowledge about the surgery and anesthesia, postoperative status and duration of hospital stay were the most frequent causes for concern during the mentioned period (Table 3).

Table 3. Questions related to opium-addicted and non-addict patients' feelings between the night before surgery and after recovery

\begin{tabular}{|c|c|c|c|}
\hline \multirow{8}{*}{$\begin{array}{l}\text { What is the last thing you remember before } \\
\text { anesthesia? }\end{array}$} & Variable & $\begin{array}{l}\text { Opium } \\
\text { addicts }\end{array}$ & Non-addicts \\
\hline & Hunger & $6 \%$ & $4 \%$ \\
\hline & Severe anxiety & $12 \%$ & $18 \%$ \\
\hline & Thinking about death & $10 \%$ & $5 \%$ \\
\hline & Thinking about family & $15 \%$ & $19 \%$ \\
\hline & Pain & $19 \%$ & $17 \%$ \\
\hline & $\begin{array}{c}\text { Questions of } \\
\text { anesthesiologist }\end{array}$ & $24 \%$ & $26 \%$ \\
\hline & Sound of devices & $14 \%$ & $11 \%$ \\
\hline \multirow{5}{*}{$\begin{array}{l}\text { What is the first thing you remember after } \\
\text { anesthesia? }\end{array}$} & Pain & $31 \%$ & $27 \%$ \\
\hline & Feat of death & $11 \%$ & $8 \%$ \\
\hline & Ambient noise & $28 \%$ & $18 \%$ \\
\hline & Other patients moaning & $11 \%$ & $9 \%$ \\
\hline & The nurse's voice & $19 \%$ & $38 \%$ \\
\hline \multirow{5}{*}{$\begin{array}{l}\text { What bothered you the most from the night before } \\
\text { the surgery until after the anesthesia? }\end{array}$} & Hunger & $17 \%$ & $21 \%$ \\
\hline & Feat & $34 \%$ & $28 \%$ \\
\hline & Pain & $14 \%$ & $11 \%$ \\
\hline & Insomnia and fatigue & $22 \%$ & $9 \%$ \\
\hline & $\begin{array}{c}\text { Lack of general } \\
\text { information about the } \\
\text { surgery, postoperative } \\
\text { status and length of } \\
\text { hospital stay }\end{array}$ & $13 \%$ & $31 \%$ \\
\hline
\end{tabular}




\section{DISCUSSION}

In the present study, we investigated the occurrence of anesthesia awareness in patients undergoing pelvic and abdominal surgeries in two hospitals in Gorgan, northeastern Iran. Based on the results, none of the opium addicts and non-addicts experienced anesthesia awareness and recall. Inconsistent with our findings, Malek et al. reported opium addiction as a risk factor for anesthesia awareness in patients undergoing abdominal surgery (11). Another study also reported that consumption of opium or alcohol increases the required dose of anesthetics as well as the risk of anesthesia awareness (16). One of the most important goals during anesthesia is to create enough anesthetic depth, which is the key factor affecting anesthesia awareness and recall. Other studies have also reported that factors such as anxiety, pain threshold and drug sensitivity could affect depth of anesthesia (15). In addition, painful stimuli can affect memory suppression and reduce the depth of anesthesia. Therefore, patients' pain and anxiety level should be considered when determining the correct dose of anesthetics in order to create sufficient anesthetic depth (17). Baghaei Wadji and colleagues stated that higher cortisol levels in opium addicts may be a contributing factor to reduced anesthetic depth and increased risk of anesthesia awareness compared to nonaddict patients ( $\underline{18})$.

Some studies have shown that preoperative injection of benzodiazepines such as midazolam in addition to sedation causes forgetfulness and reduces the recall of anesthesia events. In our study, midazolam was among the drugs that had been injected before surgery, which could be responsible in preventing anesthesia awareness and recall. Factors such as age, sex, weight, anesthesia class, type of surgery, etc. affect anesthesia awareness (15).

In a previous study, Forman claimed that patients always report a wide range of different experiences after general anesthesia including anesthesia awareness, which can be preventable or unpreventable.
The mentioned study also indicated that errors in the management and injection of anesthetics or technical errors such as serum pump failure, interruption of drug flow due to venous occlusion or leakage of anesthetic gas are often related to anesthesia awareness (16). Another study indicated that anesthesia awareness is generally more common among women and people aged over 65 years (19). Therefore, considering that anesthesia awareness can cause severe mental complications, such as posttraumatic stress syndrome, depression, anxiety attacks, sleep disorders, etc., all necessary technical precautions should be taken to prevent this issue in susceptible patients $(\underline{16})$.

According to a previous study, anesthetic drugs are absorbed less effectively in patients who are anesthetized without opioids, which increases the likelihood of anesthesia awareness. The mentioned study also claimed that women, people with underlying diseases such as hypertension and patients aged 65 years or over are at higher risk of anesthesia awareness (19).

In general, anesthesia awareness is a multifactorial issue that may be influenced by several factors, including efficacy of anesthetics, surgical procedure, gender, mental state of the patients, use of neuromuscular-blocking drugs, duration of surgery, etc. Therefore, in modern clinical practice, special attention should be paid not only to physical issues and patients' rehabilitation, but also reduction of adverse effects on patients' mental health. Therefore, continuous monitoring during surgery is recommended to reduce the risk of awakening (19).

In this study we did not monitor or determine the patients' central body temperature, which could affect the sensitivity to anesthetic drugs. Therefore, it is recommended to consider this issue when conducting future studies. Mental health follow up during the first postoperative 24 hours and two weeks after the operation seems necessary to identify possible 
nightmares or any sign of anxiety (20). Although in the present study, none of the patients had anesthesia awareness, the presence of pain may lead to consciousness and recall during anesthesia (20), which should not be neglected.

\section{CONCLUSION}

In the present study, none of the patients undergoing abdominal and pelvic surgery had anesthesia awareness. Moreover, opium addicts experience significantly higher level of anxiety the night before surgery compared to non-addicts. In addition, opium-addicted patients experience more pain immediately after recovery.

\section{ACKNOWLEDGMENTS}

This article has been derived from results of a research project approved by the Golestan University of Medical Sciences, Iran. The authors would like to thank the university staff and all participants in the study for their cooperation.

\section{DECLARATIONS \\ Funding}

This study received financial support from the Golestan University of Medical Sciences, Iran.

\section{Ethics approvals and consent to participate}

Written informed consent was obtained from all patients prior to participation in the study. The subjects were assured that their personal information remain confidential. The study received approval from the ethics committee of the Golestan University of Medical Sciences, Iran (ethics code: IR.goums.REC.1396.196).

\section{Conflict of interest}

The author declares that there is no conflict of interest regarding publication of this article.

\section{REFERENCES}

1. Khan MF, Samad K, Shamim F, Ullah H. Awareness during anesthesia--an update. Middle East Journal of Anesthesiology. 2008;19(4):723. [PubMed] [Google Scholar]

2. Cascella M. The Challenge of Accidental Awareness During General Anesthesia. General Anesthesia Research: Springer; 2020. p. 1-33. [View at Publisher] [DOI] [Google Scholar]

3. Thiele EL, Nemergut EC. Miller's Anesthesia. Anesthesia \& Analgesia. 2020;130(6):e175-e6. [View at Publisher] [DOI] [PubMed] [Google Scholar]

4. Heggy ER, Abbas SM, Abd El Mawla AG, Adolf M, Fetouh A. Intraoperative Awareness during General Anesthesia: Experience in 200 Patients in "185's Hospital for Emergency Surgeries and Burn".(An Observational Questionnairebased Study). Open Access Macedonian Journal of Medical Sciences. 2020;8(B):429-34. [View at Publisher] [DOI] [Google Scholar]

5. Cascella M, Bimonte S, Amruthraj NJ. Awareness during emergence from anesthesia: Features and future research directions. World Journal of Clinical Cases. 2020;8(2):245. [View at Publisher] [DOI] [PubMed] [Google Scholar]

6. Wu K-L, Wu Z-F, Lai M-F, Huang Y-H, Tseng W-C, Chen J-Y, et al. A 10-year retrospective analysis on the incidence of anesthesia awareness with recall in adult patients under total intravenous anesthesia. Journal of Medical Sciences. 2020;40(4):181. [View at Publisher] [DOI] [Google Scholar]

7. Sury MR. Accidental awareness during anesthesia in children. Pediatric Anesthesia. 2016;26(5):468-74. [View at Publisher] [DOI] [PubMed] [Google Scholar] 
8. Ghoneim MM, Block RI, Haffarnan M, Mathews MJ. Awareness during anesthesia: risk factors, causes and sequelae: a review of reported cases in the literature. Anesthesia \& Analgesia. 2009;108(2):527-35. [View at Publisher] [DOI] [PubMed] [Google Scholar]

9. Ambulkar RP, Agarwal V, Ranganathan P, Divatia JV. Awareness during general anesthesia: An Indian viewpoint. Journal of anaesthesiology, clinical pharmacology. 2016;32(4):453. [View at Publisher] [DOI] [PubMed] [Google Scholar]

10. Saltanovitz J. Opiate Addiction and Considerations for Anesthesia. 2019. American Association of Nurse Anesthetists. Practice Considerations 222 South Prospect Ave | Park Ridge.

11. Malek B, Seghlis R, Dabbagh A. Awareness during anesthesia in elective abdominal surgery in opium abusers. Tehran University Medical Journal. 2010;67(10). [View at Publisher] [Google Scholar]

12. Lerchl-Wanie G, Angster R. Perioperative analgesia for opioid tolerant patients. Der Anaesthesist. 2010;59(7):657. [View at Publisher] [DOI] [PubMed] [Google Scholar]

13. Bergman I, Kluger M, Short $\mathrm{T}$. Awareness during general anaesthesia: a review of 81 cases from the Anaesthetic Incident Monitoring Study. Anaesthesia. 2002;57(6):549-56. [View at Publisher] [DOI] [PubMed] [Google Scholar]

14. Liu W, Thorp T, Graham S, Aitkenhead A. Incidence of awareness with recall during general anaesthesia. Anaesthesia.
1991;46(6):435-7. [View at Publisher] [DOI] [PubMed] [Google Scholar]

15. Shahi S, Foruzesh Fard M, Sadeghi M, Shoeibi G. The incidence of awareness during general anesthesia. Anesthesiology

and Pain. 2013;4(3):47-54. [View at Publisher] [Google Scholar]

16. Forman SA, editor. Awareness during general anesthesia: concepts and controversies. Seminars in Anesthesia, perioperative medicine and pain; 2006: Elsevier. [View at Publisher] [DOI] [Google Scholar]

17. Cavaliere F, Cavaliere C. Monitoring the Depth of Anesthesia. Practical Trends in Anesthesia and Intensive Care 2019: Springer; 2020. p. 193-205. [View at Publisher] [DOI] [Google Scholar]

18. Baghaei Wadji M, Rohban M, Shabani M, Bahrampour A. The effect of opium addiction on response to major operation stress. Journal of Kerman University of Medical Sciences. 2005;12(3):159-64. [View at Publisher] [Google Scholar]

19. Hou L, Niu X, Ning X. The incidence and risk factors of intra-operative awareness during general anesthesia. International Journal of Clinical and Experimental Medicine. 2019;12(4):4375-80. [View at Publisher] [Google Scholar]

20. Tasbihgou S, Vogels M, Absalom A. Accidental awareness during general anaesthesia-a narrative review. Anaesthesia. 2018;73(1):112-22. [View at Publisher] [DOI] [PubMed] [Google Scholar]

How to Cite: Alinaghi Madah S M, Yousefi Z, Bakhsha F, Heidari Z, Halakou S, Jafari S Y et al. Evaluation of the Occurrence of Anesthesia Awareness with Recall in Opium-Addicted and Non-Addicted Patients Undergoing Pelvic and Abdominal Surgery. Journal of Clinical and Basic Research. 2021; 5 (1) :7-13 